\title{
PRODUZINDO CORPO, DOENÇA E TRATAMENTO NO AMBULATÓRIO: APRESENTAÇÃO DE CASOS E REGISTRO EM PRONTUÁRIO
}

Iara Maria de Almeida Souza

Fabiana, estudante de medicina, pouco mais de 20 anos, loura e pequena, atende à d. Magali, uma senhora que aparenta ter por volta de 60 anos, negra e muito gorda. No começo da consulta, Fabiana falava com uma voz baixa e hesitante, parecia não ter incorporado bem o seu personagem e, por isso, tentava improvisar no papel de médica, sem demonstrar muita confiança em seu desempenho. Ao longo do encontro clínico, sua performance foi ganhando mais desenvoltura. E após concluir a primeira fase da consulta em que recolheu informações sobre a paciente (quando preencheu uma ficha com dados socioeconômicos, recuperou a história da doença, ouviu os sintomas, anotou os resultados das análises laboratoriais e fez o exame clínico: tomada de pressão e freqüência cardíaca), chegou então a hora de apresentar o caso aos preceptores para que eles deliberassem acerca de tratamento e/ou prescrevessem novos exames.

Na ausência momentânea dos dois responsáveis pelo ambulatório (um cardiologista e uma endocrinologista), ela inicia a discussão do caso - ali mesmo, na sala em que há pouco prestava atendimento e em frente à paciente que fora objeto de sua atenção - com um residente de cardiologia, Alberto. A conversa entre eles flui sem problemas, até ela perguntar se pode recomendar a d. Magali que faça caminhadas. A resposta para esta questão o residente busca em um exame que mostra as zonas irrigadas ou obstruídas do coração. Comenta — sempre diante da paciente — que o caso parece ser gravíssimo, o resultado foi homogêneo e isto significa que está tudo obstruído ou desobstruído. Como ela teve um IAM e é muito gorda, diz ele, o mais provável é a primeira hipótese e o seu estado, portanto, é gravíssimo, repete ele, de modo que ela não pode ser liberada para nenhum tipo de atividade física.

Fabiana e Alberto não pareciam sentir qualquer embaraço de travar esse diálogo sobre o que dizia respeito à existência de alguém ali presente, d. Magali. Era como se aquela conversa não concernisse a uma pessoa cuja vida parecia estar em risco. Eles falavam sobre informações registradas em um prontuário, sobre imagens impressas que representavam a realidade material presente no interior de um corpo de natureza puramente material. 
A discussão deste caso tem desdobramentos interessantes, mas vou interromper a narrativa neste ponto. Até aqui tudo parece se enquadrar à perfeição na crítica usualmente feita à medicina de que ela desumaniza os pacientes ao reduzi-los a meros objetos, corpos de natureza biológica, destituídos de subjetividade e de relação com o mundo social. O que é a medicina de acordo com esta visão? Uma aplicação de conhecimentos visando a uma resposta objetiva, neutra e racional em relação a uma patologia situada no corpo.

Mas o que aconteceria se nós mudássemos um pouco o eixo da questão e, ao invés de tentar dizer o que ela é, nós a interrogássemos sobre os modos como acontece? Neste caso, se a medicina objetifica o paciente, as perguntas seriam: como se dá esse processo? Através de que práticas ela realiza a tarefa de destituir uma pessoa de suas qualidades pessoais, transformando-a em entidade material portadora de uma lesão? Quais são os procedimentos interpretativos usados para reconhecer e produzir uma versão objetiva do adoecimento, algo que é para aquele que o vive um acontecimento humano e não um mero fato biológico?

Escolher este caminho para falar da medicina e de suas formas de objetificação implica justamente não considerar objeto e objetividade como dados, mas tratá-los como uma realização prática, uma forma de enquadramento e de determinação que possui a característica de encobrir outros enquadramentos e percepções possíveis, e de deixar velado o próprio processo de interpretação envolvido na constituição da realidade objetiva.

O aprendizado dessas práticas de objetificação será enfatizado aqui. Embora possamos argumentar que a nossa cultura está impregnada da concepção trazida pela biologia, segundo a qual o corpo é uma coisa que vive em meio a outras tantas coisas de natureza material e a doença é uma entidade que possui um substrato carnal e real, quando atentamos para a experiência do nosso próprio corpo, nós não o compreendemos como uma entidade separada em física e psíquica. Nós o entendemos como um modo ambíguo de existir, reunião dessas duas dimensões, e que possui uma história sedimentada em hábitos e habilidades adquiridos ao longo de uma trajetória. Ele, portanto, não corresponde a um mero agregado de processos fisiológicos, mas a um modo de habitar o mundo (Csordas 1993; Casey 1998).

Assim, consideramos que para alguém penetrar em um universo como o da biomedicina, que concebe o corpo de modo tão distinto do que ele é para nós, nossa experiência e história, é preciso que o senso anterior de realidade que possuímos se desfaça e se reconstitua, ao menos momentaneamente. Isto demanda esforço e aprendizado não apenas de conteúdos, mas de atitudes que se formam e amadurecem na coexistência com profissionais que oferecem 
uma série de lições sobre como extrair da configuração geral que constitui uma pessoa, um caso médico (Good 1993). Nesse processo, algumas habilidades são refinadas, outras desenvolvidas e acabam por se sedimentar nos aprendizes de tal modo que se tornam uma dimensão de suas identidades.

Mais especificamente, pretendo explorar e detalhar esta questão através do exame de dois tipos de práticas fundamentais para a formação do médico, e que estão profundamente envolvidas no processo de reconstituição da pessoa como corpo objetivo, conjunto de órgãos, portador de uma lesão e objeto de intervenções médicas: a apresentação de caso e o registro da consulta em prontuário. As descrições apresentadas aqui são resultado de observação etnográfica feita em um ambulatório de cardiologia do Hospital Universitário da Universidade Federal da Bahia, que tem função assistencial e docente. Assim, vou iniciar a discussão com uma ligeira descrição do ambulatório e de seu funcionamento.

\section{Um breve esboço do ambulatório de cardiologia}

Todas as segundas e quartas-feiras, no início da tarde, eu atravessava a imensa porta de entrada do Hospital Universitário da UFBa, percorria um amplo salão até chegar a um corredor escuro e largo, com pesados bancos de madeira de um lado e do outro, repleto de pessoas. Lá, do lado esquerdo, em uma salinha quente e escura, eu encontrava alguns estudantes de medicina, residentes e médicos que ali trabalhavam. Era um ambulatório de cardiologia, cuja lida acompanhei durante dois anos - gravando consultas e entrevistas, conversando na sala de espera e observando o que se passava na preceptoria. Os pacientes atendidos - cerca de 1.000 pessoas, entre homens e mulheres, a maioria com idade acima de 50 anos, da classe trabalhadora e com pouca escolaridade - sofriam de isquemia cardíaca, dislipidemia, e um número considerável era também portador de diabetes.

No hospital, o espaço reservado ao ambulatório, emprestado pela Fisioterapia, era bastante precário e estava dividido em três salas, nas quais funcionavam seis "consultórios" separados uns dos outros por biombos feitos de lençóis. Havia a pequena sala a que me referi e que era usada como local de organização dos trabalhos e como preceptoria, onde estudantes, residentes e preceptores discutiam entre si, enquanto os pacientes aguardavam nos "consultórios" as deliberações sobre seus casos.

Cerca de 20 pessoas eram atendidas em uma tarde por seis internos, estudantes de terceiro e quarto anos que cumpriam um estágio extracurricular anual (ao todo eram 12, que se dividiam entre os dois dias de atendimento). 
Dois preceptores orientavam os estudantes e dois residentes em cardiologia os auxiliavam. Cabia aos internos atender aos pacientes, preencher uma ficha com seus dados, apresentar os casos aos preceptores, registrar a consulta em prontuário, escrever receitas e preencher formulários, realizar ainda algumas tarefas ligadas à organização do trabalho e freqüentar as sessões didáticas semanais sobre temas de cardiologia.

Durante a pesquisa, convivi mais tempo com uma turma de estudantes que tinha recém-ingressado no ambulatório. Chegaram ainda tateantes, não conheciam muito o jargão específico da cardiologia, embaraçavam-se quando o preceptor fazia alguma pergunta do tipo: "Qual a classe funcional da angina?" Ao longo do tempo foram se familiarizando com os termos e alguns chegaram a adquirir bastante fluência no uso do vocabulário médico dessa área. Entretanto, além da cardiologia e de seu jargão, os estudantes estavam aprendendo muitas outras habilidades nesse tipo de prática, como lidar com o paciente, apresentar um caso, preencher receitas, prontuários, relatórios, relacionar-se com médicos e colegas de curso.

Apesar do ar titubeante em face dos preceptores, alguns já sabiam vestir o personagem do "doutor" e representavam com bastante sucesso seu papel junto ao paciente, parecendo possuir uma espécie de interruptor que ligava ou desligava a função de "doutor". Em um instante comportavam-se como estudantes preocupados com aulas, provas ou diversão e, num piscar de olhos, transmudavam-se em médicos, com voz de autoridade e pose de quem sabe bem o que está fazendo, para logo retornarem à performance do aluno tímido diante do preceptor que os está argüindo.

Em geral, o esquema de atendimento era o seguinte: o estudante chegava por volta das 13 horas e já encontrava a agenda com a lista dos pacientes, seus prontuários e fichas empilhados por ordem de chegada. Cada um procurava um dos "consultórios" disponíveis para se estabelecer; havia certa disputa pelos melhores lugares, pois os quadrados delimitados por biombos não eram exatamente equivalentes em termos de privacidade, claridade e isolamento sonoro. A caça a cadeiras e a mesas antes de iniciar o trabalho também não chegava a ser algo inusitado. Uma vez acomodados, depois da luta por espaço e móveis, estudavam o prontuário do paciente e tinha início a consulta, ou melhor, a sua primeira fase, aquela em que eles colhiam os dados que seriam depois apresentados aos preceptores. Isto feito, os pacientes ficavam na sala de atendimento, enquanto o interno saía para fazer sua exposição do caso. Após a discussão, ao retornar, o interno trazia uma receita e a solicitação de exames para o paciente.

A ida e vinda da consulta podia durar mais de uma hora; este tempo era considerado excessivo por alguns membros da equipe do ambulatório que, 
às escondidas, teciam críticas à coordenadora. Para enfrentar a situação, os estudantes eram solicitados a abreviar o tempo da consulta. Eles, por sua vez, criticavam os colegas que se estendiam mais no atendimento. Além disso, nas discussões de caso, os preceptores acabavam por desencorajar as conversas mais longas, na medida em que insistiam para que a apresentação se limitasse apenas ao que fosse relevante para o caso.

Todo o tempo que preceptores, residentes e internos passavam no ambulatório não era, entretanto, preenchido apenas com atendimento e discussões de caso. Nos intervalos entre um caso e outro, ou quando não havia preceptor disponível, as conversas fluíam em outras direções. Nessas ocasiões, o tom das falas, permeadas de gracejos, costumava ser mais informal, mas o tema freqüentemente recaía em questões ligadas à profissão. Entre os estudantes surgiam tópicos como a especialidade a ser seguida, o tipo de prática que eles exerceriam no futuro e em que contextos. O modo como eles discorriam sobre isso revela o que Goulart (1998) já mostrou: a despeito das mudanças no mercado de trabalho da medicina, o que os estudantes ambicionam na carreira é se tornarem médicos com consultório próprio e grande clientela.

Nas conversas, contudo, não cabiam apenas questões ligadas à vida profissional. Comentários sobre a vida pessoal - a própria e a de outros colegas - casos excepcionais e entretenimento também estavam no rol dos temas que animavam os intervalos de trabalho. E havia muito espaço para humor naquela pequena sala, o que contribuía para criar uma atmosfera mais amena em um lugar onde pessoas muito jovens lidavam amiúde com situações difíceis e pacientes enfrentavam dramas pesados.

Acontecia ali no ambulatório um encontro peculiar: jovens que ouviam sofrimentos alheios conviviam com médicos situados em momentos distintos da vida e da carreira e com diferentes graus de experiência. Sem dúvida, tal fato pesa e importa em sua formação e não só no sentido mais óbvio e direto de que os estudantes estão ali para a aquisição de maior conhecimento junto daqueles que o possuem. A presença dessa pluralidade de vozes que dialogam sobre temas da profissão e do trabalho, e mesmo sobre negociações no hospital em torno do uso do espaço e dos equipamentos, permite ao estudante esboçar um perfil do que é a vida e a profissão do médico. Assim, vai se tornando mais e mais claro para ele que ser médico é algo além da simples aplicação de conhecimento científico visando intervir em um processo patológico ou lesão. E isto se dá a despeito da valorização explícita do saber técnico que se adquire na fase clínica (Menezes 2001; Ronzani e Ribeiro 2003). Esse algo além não passou sem ser notado pela reflexão das ciências sociais acerca da medicina. Vejamos, de modo muito sintético e longe de ser exaustivo, o que ela nos diz sobre isso. 


\section{Algumas notas sobre a literatura em ciências sociais acerca da medicina}

No mundo contemporâneo, tecnologia e ciência perpassam toda a nossa vida e estão intensamente incorporadas ao nosso modo ordinário de existência. A medicina é uma das esferas da vida social em que as conquistas científicas e tecnológicas se fazem presentes e se mostram espetaculares: permitem intervenções cirúrgicas mais seguras e precisas, o desvendamento de nossa programação genética, a produção de drogas mais potentes, a visualização do interior do corpo, o descobrimento de patologias que ainda não se manifestaram como sintoma etc. Ciência e técnica apontam para infinitas possibilidades de correção da natureza e nos acenam com um futuro sem doença, sem dor e, quem sabe, sem envelhecimento e morte. Ao mesmo tempo, ouvimos por toda parte vozes que falam sobre a existência de uma crise na medicina. O que essa crise tem a ver com seu lado mais potente e bem-sucedido?

A compreensão desta questão passa por uma reflexão acerca da aliança firmada entre ciência, técnica e medicina. Enquanto visões mais ingênuas podem saudar os avanços em direção ao mais saber e, conseqüentemente, às intervenções mais eficazes contra as doenças que nos afligem, o olhar lançado sobre este tema na antropologia ou na sociologia da saúde traz, em geral, uma perspectiva mais crítica. Argumenta-se - com algumas variações - que o presumido sucesso da medicina caminha lado a lado com a tendência à dominação e à normatização da existência e se dá à custa de uma atrofia das dimensões humanas envolvidas nos processos de adoecimento, tratamento e cura, uma vez que nela predomina uma concepção biologística e individualista de corpo, doença e cura (Martins 2003; Caprara e Lins e Silva 1999; Koifman 2001; Acioli 2004; Scherer et alii 2005; Martins 2004).

O modelo de entendimento da doença na medicina é o da apreensão objetiva de um evento da natureza, pretensamente fundado em certezas não-precárias, porque assentadas na suposta estabilidade das coisas e dos corpos. E para que a medicina possa cumprir com suas promessas de progresso contínuo, segundo Good (1993), o que se exige dela parece ser um compromisso com os ideais de racionalidade, neutralidade e objetividade da ciência. Acontece que a realização desses ideais nunca se dá de forma plena na clínica (tampouco nas ciências, mas este não é nosso tema aqui).

Várias questões são suscitadas quando constatamos a existência da idealização da medicina como ciência e do corpo como coisa de natureza material. Abordagens distintas procuram tratar o tema das relações entre o modelo biomédico e a clínica. Alguns autores dão mais atenção ao tipo de 
conhecimento e de raciocínio empregado pelos médicos em sua atividade. É o caso do trabalho de Camargo (2005) sobre as formas de aquisição e renovação do acervo de informações dos médicos. Ele mostra que o conhecimento usado na clínica envolve a incorporação de saberes diversos, alguns deles implícitos e contraditórios entre si e contraditórios também com a própria prática. Tal fato aponta para uma distinção fundamental entre o conhecimento que opera na medicina clínica, supostamente fundado na ciência médica, e a imagem que temos da ciência como atividade metódica, racional e coerente.

Koifman (2001) também se volta para a questão do conhecimento ao analisar a reforma curricular da Universidade Federal Fluminense em 1992, orientada por uma visão mais humanista da prática médica. Assim como Camargo, ela assinala a presença de visões fragmentárias e contraditórias na medicina e a impossibilidade de pensar seu conhecimento e sua prática como algo que tenha a universalidade de um conceito científico. O reconhecimento do inevitável entrelaçamento entre o saber médico e seu contexto de aplicação não impede a autora, entretanto, de assinalar o predomínio na medicina de uma perspectiva biologicista, pautada na especialização, centrada cada vez mais no uso de tecnologia, fato que dificulta uma integração efetiva das dimensões subjetivas e sociais em sua prática. Aqui já vemos a emergência de uma outra questão: já que o padrão biomédico de cientificidade, que impera na medicina, não se realiza de modo nenhum conforme o modelo idealizado, como ele se faz presente na clínica? Quais são as conseqüências da adoção desse padrão para os momentos de encontro entre o médico e seu paciente?

Estudos de clara inspiração foucaultiana consideram que esse entendimento materialista e mecanicista do corpo, componente essencial da configuração médica, implica um reducionismo biológico e uma destituição do paciente de seu direito sobre o corpo, direito de "viver, adoecer e morrer do modo que mais lhe aprouver" (Martins 2004:22). Além disso, a medicina é caracterizada como uma esfera de atividade afinada com o processo mais geral, presente em nossa sociedade, de normatização da vida e da existência. Aliada à crítica à submissão dos indivíduos aos mecanismos difusos de poder e dominação, temos aqui uma tentativa de desvelar a face moral e a dimensão política da medicina, encobertas por sua pretensa cientificidade e universalidade de seu saber, que a leva a adotar uma posição totalitária quando confunde os aspectos quantificáveis da realidade com a realidade em si mesma.

Outros estudos não enfatizam tanto os aspectos morais ou políticos da ciência médica mas, visando elucidar a dinâmica que une a medicina a 
outras esferas da vida social, apontam também para as relações entre esta e o mercado. Por exemplo, argumenta-se que os interesses do capital insuflam a produção e o uso de tecnologia e acabam por transformar médicos e pacientes em insumos na produção - algo que atrofia seriamente a dimensão cuidadora da medicina (Merhy 2000). Um dos problemas em relação a essas afirmações é que elas são enunciadas de um modo tão genérico e aparentemente tão evidente que perdem de vista o fato de que o capital só se faz presente na clínica por uma série de mediações. E se ele de fato transforma todos em meros instrumentos de sua engrenagem, é preciso evidenciar as formas pelas quais isso se dá na prática. Uma visão mais próxima das ações e das experiências é algo que falta a estudos deste tipo.

Sem negligenciar o peso da ciência e da tecnologia na medicina (e sua relação com outros domínios sociais como o mercado ou a política), alguns autores argumentam, entretanto, que a clínica não se resume à aplicação de técnica e de conhecimento. Schreiber (1997) chama a atenção para a ancoragem da prática em contextos pragmáticos específicos, que condicionam os modos como o profissional vai desenvolver suas atividades. A dupla face da medicina - de um lado, arte; de outro, ciência - também é tomada como tema, além de diversos contrastes que palpitam no dia-adia do médico: deveres/dificuldades, técnica/ética, aspectos físicos/aspectos comunicacionais. A tensão existente entre estes dois pólos de atração torna o ato médico particularmente difícil. Segundo a autora, o fato de que em nossa cultura estejamos inclinados à busca de certezas e garantias dadas pela tecnologia e pela ciência, ou melhor, pela imagem projetada destas últimas, não anula a presença de subjetividade e julgamento; assim, nos momentos de incerteza, os médicos devem se deixar guiar antes de tudo pela ética nessas situações.

Ao seguir essa trilha que conduz à descoberta de elementos supostamente alheios à ciência, mas evidentes na medicina, chegamos às emoções. $\mathrm{O}$ afeto, sobre o qual nos acostumamos a pensar como algo que perturba a neutralidade requerida por qualquer prática científica, não deixa de revelar a sua presença aos olhares atentos daqueles que vão buscá-lo nas falas e nas ações. Mas as coisas não são tão simples assim. O curso e o currículo nada dizem sobre como lidar com a morte e o sofrimento que chega com ela e, dessa maneira, acaba por conduzir o estudante a uma negação e a uma tentativa de descolamento em relação às suas emoções (Quintana et alii 2002; Menezes 2001; Souza 2004; Hoffmann 1993). Um dos modos de ocultar a inquietação trazida pela morte é tratá-la como probabilidade estatística ou um mero evento natural. Para Bonet (2004), o "sentir", em seu significado mais amplo — não só a dor causada pela morte de um paciente — 
está presente na clínica e constitui um dos eixos da tensão estruturante do campo biomédico, ao lado do saber que, durante certo tempo, foi a dimensão privilegiada quando se falava de medicina.

A tentativa de dar visibilidade àqueles aspectos pouco explorados quando o tema é a medicina - sua dimensão artística (Schreiber 1997), as emoções (Bonet 2004), a cultura (Souza 2001; Gilbert et alii 2006), as difíceis decisões éticas (Menezes 2001) - renovou nas ciências sociais a visão sobre ela. Acredito que esse movimento não envolve só uma mudança analítica ou conceitual, mas se deve também a uma virada metodológica na direção da etnografia. Estudos realizados em hospitais, CTIs, ambulatórios, clínicas médicas especificam e dão novo tom e coloridos, colocando em uma outra chave temas já tradicionais nos estudos sobre a profissão médica. Sem dúvida, é mais fácil matizar aquele modelo genérico que trata a medicina como uma atividade que objetifica o paciente, que reduz a instrumentos os seus profissionais e usuários, quando vemos as situações concretas em que os médicos atuam e nas quais lidam com pessoas bem reais. Isto não quer dizer que não haja objetificação, mas que na prática ela vai sempre se combinar ou entrar em conflito com vários outros aspectos, já apontados, envolvidos em seu exercício.

Há, contudo, algo que me parece carecer ainda de um olhar mais detalhado. Esse algo é justamente o mais unânime e óbvio aspecto da prática médica: os processos de objetificação. Quando a complexidade e a multiplicidade de conhecimentos, contextos e modos de atuação dos médicos são tornados visíveis, há uma tendência a se enfatizar a significância daquilo que contradiz ou matiza a objetividade, enquanto esta é tratada como um dado. É o momento talvez de retomarmos a nossa velha conhecida - freqüentemente nosso objeto de crítica - e observá-la com o mesmo olhar cuidadoso que lançamos aos significados humanos, sociais e existenciais da medicina. Um breve olhar sobre estas duas práticas formativas - a apresentação de caso e o registro da consulta em prontuário que são, como Good (1993) argumenta, essenciais na formação do médico) — vai nos permitir uma entrada no terreno das práticas interpretativas envolvidas na objetificação do paciente. ${ }^{1}$

\section{A discussão de casos}

A entrada do estudante no mundo da medicina começa pelas ciências biomédicas: fisiologia, anatomia, bioquímica etc. É por aí que ele ingressa no reino dos corpos despersonalizados; a princípio, ao estudar anatomia, ele não se depara sequer com cadáveres conservados em sua integridade, mas 
com peças anatômicas (Quintana et alii 2002). Os passos iniciais dos estudantes, portanto, são conduzidos pelas ciências que tratam o corpo como objeto mecânico e passivo (Goulart 1998). Além disso, a epistemologia incorporada ao currículo - manifesto ou oculto - da maioria das escolas de medicina pensa a ciência como um conjunto de fatos estabelecidos, ou ao menos passíveis de resolução, e o mundo como um aglomerado de unidades atomizadas, sem enfatizar a natureza provisória e contingente de qualquer conhecimento (Atkinson 1984; Corrêa 1995). Só depois de travar contato com essas ciências e com corpos mortos e fragmentados é que o estudante é autorizado a lidar com os vivos, passando então a conviver com pacientes em hospitais ou ambulatórios (Goulart 1998).

O advento do aprendizado clínico para o estudante é marcado pela experiência do contato direto com o paciente e sua doença, algo que ele só conhecia teoricamente. Ele agora é posto frente a frente com casos concretos aos quais tem que responder. A idéia que subjaz à imposição desse tipo de aprendizado é de que assim o estudante pode sedimentar o que foi visto nas disciplinas teóricas, ganhar habilidade e aprender sobre a atitude correta em face da doença e do paciente (Sinclair 1997; Hobbs 2002; Geller et alii 1990).

No ambulatório estudado, os internos não discutem os casos diante dos pacientes (o caso que apresentei no início deste artigo é uma exceção). Em geral, eles chegam à sala onde estão os preceptores com as mãos repletas de papéis: o prontuário do hospital, a ficha do ambulatório e os resultados de exames trazidos pelo paciente. Nessa conversa, eles devem exibir as novas e distintas habilidades que lhes são exigidas, têm que mostrar que aprenderam a apalpar, auscultar, escrever na linguagem formalizada dos prontuários, falar com o paciente, os preceptores e os residentes. Ao preceptor cabe orientar acerca de como reconhecer e avaliar certos sinais e sintomas, como analisar um caso ou os exames, qual o parâmetro de normalidade desejado e possível naquela circunstância, quais os procedimentos usados para tratar aquela doença. Além disso, eles podem dar indicações de como considerar (ou desconsiderar) o paciente, e um ou outro acaba por se tornar modelo para o estudante daquilo que um médico deve ser e de como deve se portar na sua profissão. Os residentes estão nesse contexto ocupando uma posição intermediária; eles auxiliam nas discussões de caso, têm mobilidade para sair e ver filmes de cateterismo, mas não são plenamente autorizados como os preceptores.

Segundo Sinclair (1997), nesse momento o que é crucial para o estudante não é tanto a relação com os pacientes, mas com os preceptores, porque são eles que o avaliam continuamente - e a avaliação repercute 
em sua carreira. O desempenho do aluno nesse ambulatório era estimado, levado em consideração, sem dúvida, mas não por meio da atribuição de uma nota; eles também não careciam de uma aprovação ao final do período para seguir adiante. Entretanto, havia certos mecanismos que mostravam claramente que a atuação deles estava sendo avaliada. Um dos modos de mostrar apreço pelo empenho do aluno era oferecer a ele uma bolsa remunerada para que permanecesse ligado ao ambulatório trabalhando em pesquisa ou como monitor da turma que entraria posteriormente. Além disso, não raro os estudantes precisavam de cartas de recomendação para se incorporarem como estagiários em outros locais de ensino e pesquisa. Usualmente apenas aqueles que se julgavam com chance solicitavam tais cartas aos preceptores; os que haviam revelado senso de compromisso (pontualidade e assiduidade, cuidado no trato com as rotinas e os procedimentos organizados, interesse no aprendizado dos conteúdos) obtinham uma elogiosa apresentação e indicação para ocupar a posição que almejavam em outro lugar. Por outro lado, houve um caso em que um estudante, por ter uma conduta considerada negligente com o trabalho, foi desligado do ambulatório.

Ainda que outros elementos entrassem na avaliação do estudante, decisivo para seu julgamento era, de fato, a sua atuação na apresentação de caso. Nesse momento, suas qualidades deviam ser exibidas (seriedade, capacidade de conversar com o paciente, de conduzir um exame físico, conhecimento do jargão e do tema).

A apresentação costumava ser iniciada com a informação acerca do sexo e da idade do paciente; eventualmente se dizia seu nome, embora boa parte das vezes a pessoa atendida fosse anônima. Em seguida, começava a descrição da doença e sua história, que podia ser algo assim: paciente com história de IAM (infarto agudo do miocárdio); há três anos fez uma angioplastia, com stent ou sem stent (dispositivo para manter a abertura da artéria), ou revascularização miocárdica completa ou incompleta (completa quer dizer que as artérias obstruídas foram desobstruídas; incompleta significa que restam ainda obstruções), hipertensão há cinco anos e diabetes mellitus tipo 2 há três anos. Essas informações podiam parecer insuficientes para alguns médicos, que solicitavam ao estudante que descrevesse o estado das artérias coronarianas do paciente, que paredes haviam sofrido danos etc.

A história do paciente contada pelo estudante é a de um processo de doença, localizada temporal e espacialmente em lesões de tecido e em disfunções nos processos fisiológicos. Na narrativa tecida durante a apresentação de caso, a pessoa que padece de uma aflição deve ser apresentada como o lócus onde se dá a doença. Pode-se dizer que por um processo metonímico pessoa e doença confundem-se (Gilbert et alii 2006). O gênero narrativo da 
apresentação de caso, que o estudante deve dominar, implica a construção de um relato, através do qual a "pessoa é formulada como paciente e como problema médico" (Good 1993:79).

Para essa formulação, não importa só a doença e seu tempo, mas é fundamental também o relato acerca dos sintomas. As queixas do paciente, como ele vem se sentindo, se tem dor, falta de ar, cansaço, tontura, tudo isso é argüido na consulta. Se há sintomas, é necessário que eles sejam enquadrados como decorrentes (ou não) de problema cardíaco e é preciso também tentar estabelecer o que eles indicam. A questão aqui não é usar sintomas para guiar a construção de um possível diagnóstico, pois os pacientes já chegam ao ambulatório identificados como portadores de cardiopatia isquêmica e dislipidemia. O que se pretende é construir um quadro de sua condição atual através da interpretação dos sintomas, mas principalmente dos exames que mostrarão se existe um "substrato real" para suas queixas.

A dor no peito é entre todos os sintomas aquele que merece mais atenção. É preciso que na consulta as sensações do paciente sejam bem exploradas para que o relato do estudante traga elementos suficientes para caracterizar a dor como angina (decorrente da isquemia) ou como uma dor de outra natureza localizada no peito. Os preceptores, durante esse momento da discussão de caso, costumam propor uma série de questões aos estudantes a fim de que eles especifiquem o que o paciente sente, de tal forma que seja possível dizer se a dor segue um padrão típico de angina e, neste caso, se é estável ou instável, de classe funcional $1,2,3$. Caso as respostas dadas pelo estudante tragam informações escassas e precárias, ele ouve, um tanto envergonhado, a recomendação do médico para que retorne ao consultório e "questione melhor o paciente". Esta exigência de uma descrição detalhada e clara da dor é justificada pelo preceptor: a dor, por ser um sofrimento subjetivo, exige uma investigação meticulosa que permita depurá-la dos elementos pessoais até que reste apenas a informação capaz de garantir um enquadramento adequado do sintoma. Tal depuração é um dos mecanismos utilizados para determinar o dado objetivo daquilo que parece ser o mais subjetivo: o sofrimento do paciente.

Entretanto, por mais típica que seja, a dor não é o critério único para definir diagnóstico ou tratamento. A narrativa do paciente é considerada uma espécie de véu através do qual se pode entrever a doença, mas não é um testemunho objetivo da sua condição, portanto, serve apenas como uma indicação que deve encontrar confirmação em evidências mais seguras: os exames - especialmente aqueles que envolvem o uso de tecnologia da imagem — que permitem a visualização das artérias, da musculatura do coração, das áreas irrigadas e obstruídas etc. e são cruciais para se chegar ao que é real na doença. As imagens e os resultados obtidos através delas, embora envolvam interpretação, são tratados como represen- 
tações diretas, sem mediações, do interior do corpo (Monteiro 2004; Joyce 2005). O privilégio concedido a esse tipo de exame revela-se em vários momentos, por exemplo, no início da exposição dos casos quando médicos exigem dos estudantes a informação sobre obstrução das artérias e o estado das paredes cardíacas (quais as lesionadas e quais não o são). Ou quando determinam a condução dos casos, usando-os como principal guia, como o trecho apresentado no início deste artigo.

Contudo, aparecem por vezes divergências entre o que é narrado pelo paciente ao estudante e o que as imagens dizem. A tentativa de dar conta das discrepâncias conduz, nas situações problemáticas, a um reconhecimento da existência de processos interpretativos na avaliação dos exames. Nesses momentos, suspende-se a crença na imagem como representação que espelha fielmente o interior do corpo. Ainda assim, não se instala uma dúvida radical ou se abre espaço para uma relativização do modelo de corpo e de doença no qual se assenta a medicina. Pondera-se apenas que nem todos os exames são dotados do mesmo grau de objetividade; sendo assim, o mais prudente é que o médico apóie sua decisão em um conjunto de exames, cuja análise conferirá mais segurança à decisão a ser tomada.

Vejamos como exemplo: o dr. Alberto discutia um caso com Michele, interna, que começou dizendo: "Rosa, paciente de 36 anos, teve um episódio de IAM há dois anos". A paciente tinha os índices bem controlados de HDL, de LDL etc. O cateterismo revelava apenas uma obstrução de 50\% (só é considerada lesão grave quando a obstrução está acima de $75 \%$ ) em uma artéria importante e nada mais. A despeito de ter uma lesão que não era significativa, segundo Michele, ela se queixava de dor no peito quando estava sob tensão emocional; entretanto, a dor não era desencadeada por esforço físico. Ao comentar o caso, o médico de início fez uma exposição acerca das causas de infartos quando há uma lesão de $50 \%$ : o problema não reside no grau de obstrução da artéria, mas na qualidade da placa, que solta uma espécie de trombo e entope a artéria. Em seguida, ele argumentou que no caso em questão talvez o problema não fosse mesmo da artéria ou da placa, mas do resultado do CAT, que depende da interpretação daquele que vê o filme. Disse ele: é possível que um profissional fale que a artéria está com $50 \%$ de obstrução e isto é algo "subjetivo", pois outro médico, ao ver o mesmo filme, pode afirmar que a obstrução é de $75 \%$ ou mais. O CAT traz uma carga de subjetividade e, portanto, pode não traduzir bem a realidade. Para ele, a objetividade dos fatos deve ser estabelecida com a realização de outros exames, que permitirão chegar a alguma certeza sobre a procedência ou não da queixa. Esta será real se estiver sustentada por uma lesão verdadeira, detectável pelo uso desses vários instrumentos. 
O fato nos leva a pensar na objetividade como algo para o qual se converge, quando são reunidos os elementos e são aplainadas ou eliminadas as possíveis discrepâncias entre eles. A "realidade objetiva" da doença resulta, portanto, da adoção de um procedimento interpretativo, entretanto, quando o processo é concluído, ela surge como algo que já estava lá desde o início, apenas esperando para ser descoberta.

Mas vamos continuar com a apresentação de caso: depois que o interno trata dos sintomas, é a vez do exame clínico - o estudante sempre informa sobre o pulso e a tensão arterial e, embora o exame envolva ausculta, palpação, qualquer outro elemento só é mencionado se for encontrado algo de positivo, ou seja, algo que indique um problema, como edemas, crepitações no pulmão etc. Um relato excessivamente detalhado é motivo de censura; recomenda-se àqueles mais seduzidos por miudezas e preciosidades que se atenham apenas ao que é importante. A clareza do estudante acerca do que é relevante revela para os preceptores o aprendizado do estilo narrativo da apresentação de caso e seu grau de amadurecimento. Por outro lado, não devemos esquecer que mesmo em um ambulatório em que a consulta é demorada — ou talvez por isso mesmo - a questão do tempo é crítica. Assim, a exigência de concisão na apresentação está ligada não só ao conhecimento das regras da boa apresentação, como se justifica pela escassez de tempo de atendimento.

Há também uma necessidade de lógica naquilo que é falado — se o estudante relata algum achado, precisa esclarecer quais as suas implicações para o caso em questão. Se não o faz espontaneamente, o preceptor propõe questões que ele deve tentar responder e justificar. As perguntas feitas pelo médico são típicas questões do mestre: ele sabe a reposta, interessa-lhe testar o estudante, saber se ele é capaz de discernir o que é correto na situação. Quando ele diz "qual a classe funcional da angina?", ele espera que o estudante não apenas cite um número, mas também explique por que enquadrou o caso nessa categoria. É preciso, portanto, a apresentação de um argumento lógico. A narrativa em sua totalidade deve ser um relato conciso e coerentepara isso, é imprescindível que o estudante sintetize as respostas extensas que ouviu do paciente, selecionando só aquilo que julga ser relevante.

O próximo passo na construção do caso, depois do exame clínico, é a exposição dos resultados de exames laboratoriais ou outros. São apresentadas as taxas de glicemia, colesterol LDL e HDL, potássio, TGO e TGP (enzimas hepáticas) e o que mais for conhecido. O estudante pode adotar duas estratégias: dizer apenas o que ele julga estar alterado ou arrolar todos os resultados. Nesse momento da apresentação do caso, os preceptores parecem ter mais dificuldade em apreender o significado dos dados apresentados exclusivamente pelo que ouvem e, por isso, é comum que se inclinem para 
o estudante e lancem os olhos na folha de prontuário em suas mãos, a fim de lerem o que está anotado.

Certamente não é muito fácil atentar para informações e formular uma síntese do paciente só pelo arrolar de uma série de siglas e de quantidades. Justamente aquilo que é pura quantificação — ideal da boa ciência — não é capaz de atrair espontaneamente a atenção do preceptor. Pelo contrário, ele se dá conta de que corre o risco de se dispersar e realiza um esforço deliberado para concentrar-se nessa informação, esforço que não parece tão evidente, por exemplo, quando ele ouve um relato de sintomas. É possível que aquilo que traz uma significação humana e nos aproxima da experiência do outro evoque um tipo de compreensão mais imediata, não ausente da clínica, bastante distinta do entendimento que tem lugar quando apreendemos a realidade através das fórmulas ou das quantidades. $\mathrm{O}$ fato acontece a despeito da valorização na medicina do que é validado com a mediação de instrumentos que mensuram os processos fisiológicos, as lesões etc.

Ao dar seguimento à discussão, chega o momento de o estudante falar dos medicamentos prescritos para o paciente. Aí entra mais uma vez o problema relativo à distinção entre o que é objetivo e o que é subjetivo. Neste caso, a questão coloca-se nos seguintes termos: é preciso distinguir claramente entre o que é prescrito e o que é usado. Assim, é possível reconhecer os efeitos reais da droga sobre o paciente. Por exemplo, na apresentação de um caso se dá o seguinte diálogo entre a estudante e o preceptor:

\section{Preceptor: - Ela está tomando um ou dois por dia?}

Interno: - Dois, de 12 em 12 horas, eu vi na receita.

Preceptor: - Na receita é uma coisa, o que ela está tomando é outra. Interrogue se ela está realmente tomando, porque a pressão está alta, mas eu estou achando complicado aumentar mais um medicamento para ela.

A informação sobre o uso da droga é fundamental para que se possa deliberar sobre o rumo do tratamento: alterar ou manter a prescrição. Os fármacos constituem a principal estratégia terapêutica empregada pelos médicos, e a maioria dos pacientes toma uma quantidade razoável de drogas, portanto, é de se esperar que eles nem sempre cumpram com todas as determinações de horários e quantidades; assim, é preciso saber, quando algo não anda bem, se isto se deve a uma falha ou insuficiência do remédio (aspecto objetivo) ou a um uso inadequado (aspecto subjetivo).

Apresentados os dados sobre o paciente, ou seja, uma vez que ele foi posto como um problema médico à espera de uma resolução, é chegada a hora de determinar o que é possível fazer em relação a ele para minimizar 
os seus sintomas - se ele os tiver - e para tentar alcançar ou manter o perfil desejável, isto é, a pressão arterial, a freqüência cardíaca, a glicemia, os triglicerídeos, o HDL e o LDL e outros índices nos níveis recomendados. O objetivo é "otimizar" o paciente, enquadrá-lo nos padrões estabelecidos de normalidade. Ao se estabelecer um perfil como meta a ser alcançada, buscam-se quais e quantas são as drogas adequadas para se chegar a ela. Vários elementos são considerados explicitamente quando o preceptor recomenda a prescrição de um remédio: os custos que estes têm para um paciente do SUS, por exemplo, mas principalmente conta o fato de um medicamento aumentar a sobrevida e não apenas melhorar os sintomas.

O momento de deliberar sobre medicamentos é um dos preferidos do preceptor para colocar a sua pergunta de mestre: "o que você recomendaria para este paciente?". Em casos aparentemente mais simples os estudantes arriscam uma resposta, como aumentar a dose do anti-hipertensivo. Mas nas situações mais complexas eles costumam calar, olhar para o chão e esperar pela resposta. Diferente do que Good (1993) apontou em seu estudo — que os estudantes tinham certo senso de que havia algo de arbitrário na escolha da medicação recomendada - nas discussões de caso que observei, nenhum estudante pôs em questão a determinação do médico. É bem verdade que esta atitude de aceitação poderia corresponder a uma avaliação por parte do estudante de que não valia a pena explicitar dúvida ou desacordo em relação ao que o preceptor ou o residente havia estabelecido. No entanto, o que posso afirmar é que não existia conflito aberto quanto à deliberação do preceptor sobre o caso.

A marcada preferência dos médicos pela prescrição de medicamentos, relativamente a outras estratégias possíveis — como a realização de dietas e exercícios físicos - deve-se, segundo dizem, à maior confiabilidade, presteza e eficácia dos medicamentos, pois não lhes parece muito razoável esperar a adesão dos pacientes a um estilo de vida repleto de restrições e preceitos, nem esperar o longo tempo necessário para que uma mudança de hábitos produza seus efeitos. Aqui temos uma oposição entre o efeito objetivo, implacável e rápido da droga e a incerteza de contar com algo de natureza "subjetiva", como a vontade do paciente para reformular a sua conduta.

A prescrição de medicamentos é a deliberação mais comum ao final de uma apresentação de caso, mas não é raro que sejam tecidas considerações acerca da solicitação de exames além daqueles que fazem parte da rotina do ambulatório. Neste caso, o preceptor explica ao estudante o porquê da solicitação e como é o preenchimento dos relatórios e dos formulários de requisição que são exigidos para alguns exames de alto custo e complexidade.

Por exemplo, o preceptor diz à interna: "O teste ergométrico é bom para o paciente que você já sabe que tem cardiopatia. Você vai botando carga, se 
passar do terceiro estágio, o prognóstico é bom. Se o paciente fica no terceiro estágio, se fica no terceiro, a chance é de menos de $1 \%$ de ter algo no próximo ano. Com o teste ergométrico, o que você quer não é diagnóstico. Eu sei que ela já tem lesão de $75 \%$ na DA proximal. Eu quero saber como ela se comporta, se a paciente evolui com dor. Na solicitação, você coloca 'paciente cardiopata, teste para avaliar a condição clínica'".

Este trecho não só mostra o estilo didático da apresentação de caso em que o preceptor não apenas delibera sobre o que solicitar, mas fornece ao interno uma justificativa sobre a conduta adotada - , mas também é revelador do modo como se lida com a incerteza acerca do futuro do paciente. Os resultados de exames dizem quais são as chances do paciente sobreviver por certo período quantificável de tempo; a expectativa em relação ao futuro converte-se em cálculo e, portanto, toma a forma da objetividade dada pelos números.

Uma outra maneira de lidar com a incerteza - além do cálculo - é o recurso aos Guidelines ou Consensos, que trazem uma série de respostas padronizadas para os casos que podem ser encontrados na clínica (Berg et alii 2000). Um dos médicos sempre trazia o seu Consenso de Cardiologia, lia-o em intervalos de consultas e às vezes dirigia perguntas aos outros médicos, por exemplo: "Com qual paciente com angina você não usa nitrato?"; — "Meu? Nenhum. Em geral eu uso nitrato e..."; - "Mas o Guideline diz para começar com beta, antagonista de cálcio e, por fim, nitrato. Quase ninguém faz isso". Mesmo reconhecendo que há uma distância entre o que se preconiza pelo consenso e o que se pratica usualmente, ele não deixa de se referir a este último quando faz certas escolhas, como forma de legitimar uma decisão e fazê-la parecer não-arbitrária ou mero fruto de uma preferência pessoal.

A apresentação do caso é concluída com o estudante escrevendo a receita e as solicitações de exames ou procedimentos. É isto que ele leva usualmente em seu retorno à consulta depois da conversa com o preceptor. Às vezes leva também um arsenal retórico - nem sempre apropriado ou eficiente - para explicar ao paciente por que a medicação foi modificada ou por que determinado exame ou procedimento foi solicitado.

A discussão de casos é concluída; nela o paciente foi colocado como um problema médico e uma solução foi projetada para ele (Good 1993). Da apresentação feita pelo estudante, todos os temas da consulta que não eram diretamente relevantes para a condução do tratamento foram (ou deveriam ter sido) excluídos. Portanto, os estudantes precisam remover o que é supérfluo, aprender o que é relevante e apresentá-lo de modo persuasivo (Cox 2001; Geller et alii 1990; Haber e Lingard 2001; Lingard et alii 2003). O estilo narrativo e argumentativo, mediante o qual a história do paciente se converte em um caso, revela um dos motivos dominantes do discurso dos 
profissionais de saúde: a produção e a asseguração da objetividade científica (Haber e Lingard 2001; Lingard et alii 2003). Vimos como isso é manejado através de alguns recursos interpretativos: a depuração dos sintomas daquilo que eles têm de subjetivo, a busca de evidência em exames, a especificação do modo de uso da droga, entre outros procedimentos.

No entanto, a fala sobre os pacientes na apresentação dos casos não é apenas descritiva: é constitutiva, na medida em que formula a pessoa como paciente, e é persuasiva, pois visa convencer a audiência, cujos membros são os preceptores, de que o estudante tem as habilidades que são esperadas dele. A fala é também orientada pela escrita - o que foi registrado no prontuário - por isso, não é redundante nem repetitiva, mas pretende ser precisa, científica e não-ambígua. Vamos agora ao prontuário.

\section{Os prontuários médicos}

O processo de formação do médico envolve não apenas aprender a conduzir uma consulta, apresentar casos, prescrever remédios, mas também escrever prontuários. É pelos prontuários que, na maior parte das vezes, o estudante inicia seu trabalho no ambulatório. Antes de qualquer conversa com o paciente, ele estuda o que já está documentado sobre a sua história. Nas pastas pardas estão arquivados não só resultados de exames, mas também as consultas feitas em outros ambulatórios, os internamentos etc. Ao final da consulta, o estudante vai acrescentar ao prontuário mais uma página, uma folha padronizada, cujo conteúdo deveria também ser padronizado, na qual se registra em linhas gerais o seguinte: o diagnóstico expresso por uma sigla (por exemplo, DAC - Doença da Artéria Coronária), se o paciente tem ou teve infarto (IAM, no prontuário), há quanto tempo, o resultado de cateterismo com informações sobre a data de sua realização e outros dados: as artérias obstruídas e o grau de obstrução. Também essa descrição depende de um conhecimento das siglas (DA, CD etc. que são artérias do coração).

Em seguida, são arroladas as doenças associadas ao problema cardíaco: HAS (hipertensão arterial), DM II (diabetes mellitus tipo dois), dislipidemia, insuficiência renal, ou outras. Ao lado das informações sobre as doenças deve constar o seu tempo. O período referido, medido em meses ou anos, não diz respeito ao padecimento de uma doença pelo paciente, mas ao tempo transcorrido desde que ela foi diagnosticada. Em seguida a essa abertura com as doenças e sua história (traduzida não em acontecimentos, mas em unidades cronológicas, anos ou meses), temos os sintomas referidos pelos pacientes; se estes não mencionam nenhum, há alguns deles que devem ser 
declarados mesmo quando ausentes, escrevendo-se, por exemplo: paciente nega dor, edema etc. Ou quando o paciente se queixa de algo, coloca-se: paciente refere dor ou cansaço, ou similar. Esse uso do discurso indireto é um recurso do estudante e do médico para não se comprometerem com o que é dito pelo paciente. Ele não pode falar que o paciente sente dor, ou tem gases, mas que o paciente nega, refere ou relata algo. Em seguida, temos o resultado do exame clínico; a pressão e a freqüência são sempre anotados, mas os demais itens, como na apresentação de caso, só são escritos se algo de positivo for encontrado. São colocados os resultados de outros exames e a nova prescrição.

O prontuário, apesar de supostamente próximo da narrativa do paciente, não é uma transcrição direta da consulta, é uma reorganização, uma edição da conversa com o paciente (Berg 1996; Cox 2001; Good 1993). Por outro lado, nem tudo que está registrado é tema da consulta (freqüentemente as anotações sobre diagnóstico e o estado das artérias são copiados de consultas anteriores, já que os dados do cateterismo não precisam e nem podem ser atualizados a cada nova ida ao médico). Há, entretanto, uma semelhança muito grande entre a apresentação e o prontuário.

A ordem do que é dito ao preceptor segue mais ou menos aquela do escrito - de fato, os estudantes têm a folha dos prontuários à mão quando apresentam o caso, pois ali estão disponíveis as informações necessárias para a discussão (embora nem sempre estas sejam suficientes). Os preceptores, por sua vez, de forma reiterada, ouvem e lêem ao mesmo tempo o papel nas mãos do interno ou, o que não é raro, ao invés de atentarem para o estudante que está narrando o caso, fixam seus olhos no papel e não no interlocutor.

Em situações assim, é comum encontrarmos o que registramos a seguir: Danilo, interno, começa a narrar o caso; o dr. Marcelo, preceptor, está com uma expressão desatenta (ele se justificou antes: deu plantão na noite anterior e estava cansado). Danilo percebe a distração e olha insistentemente para ele como que solicitando a sua atenção. Quando a fala do estudante chega ao final, Marcelo pega de suas mãos o papel das anotações e, então, se concentra no caso; olha a folha longamente, refletindo - parece que é mais fácil pensar olhando para o papel, pois ali todas as informações estão reunidas e próximas, a pessoa pode ir e voltar de uma a outra, sem respeitar uma seqüência dada, estabelecendo sua própria ordem. A forma como o olhar percorre várias vezes, para cima e para baixo, a folha de papel tomada da mão do estudante sugere também que os preceptores, ao fazerem isto, estão tentando, a partir das anotações, obter uma imagem ou a visão geral do paciente, o que emergiria dos diferentes itens que compõem o registro do prontuário. Como mencionamos antes acerca das discussões de caso, 
a objetividade resulta de uma síntese construída a partir de uma série de elementos e do modo como eles convergem. Aqui também a figura do paciente é forjada mediante um processo de interpretação do qual surge uma configuração geral, embora ela possa parecer ter estado lá desde sempre.

O modelo de prontuário bem escrito é ordenado, objetivo, não-ambíguo, com todas as informações necessárias. Esta exigência revela-se no estilo literário peculiar do prontuário. Por exemplo, ao contrário do que se dá em outros gêneros, aqui as variações, a criatividade, a riqueza léxica e a conjugação de elementos retóricos são desprezadas; o que vale é uma escrita sem colorido, metáforas ou imaginação, burocrática e rígida, sem nada de contestável ou de impressão pessoal (Hobbs 2002). As palavras escolhidas são as que fazem parte do jargão e, se for possível, deve-se usar siglas para economizar o tempo de quem escreve.

Se o estudante sabe apenas o que o paciente diz (aliás, nos registros, o paciente nunca fala, diz ou sente, ele apenas "refere"), deve procurar a expressão correta no vocabulário médico para descrever o que foi dito. Certo dia, no ambulatório e na ausência temporária dos preceptores, vários estudantes estavam empenhados em ajudar uma colega a encontrar o termo adequado para escrever no prontuário que o paciente tinha gases. O consenso estabeleceu-se e flatulência foi considerado o termo mais apropriado. A importância dada à palavra revela o peso que tem a aquisição da linguagem correta para que o estudante projete uma imagem profissional, sancionada no mundo clínico, posto que os ouvidos médicos estão sintonizados na freqüência de um fraseado compartilhado (Lingard et alii 2003). A escolha das palavras, o estilo plano e não-ambíguo do prontuário está relacionado também com sua dimensão funcional: é um documento para ser lido rapidamente e deve contar de modo linear uma história, sem as idas e vindas que são características da existência. Ele revela um passado que não muda, uma geografia do corpo do paciente com suas lesões localizadas no espaço interior da matéria.

Posto que o registro é um documento legal e formal da instituição, ele também autoriza o estudante (Good 1993). Ao fazer um ligeiro desvio aqui, quero mencionar que eu não tinha muita idéia do quanto pesava para o estudante sentir-se autorizado, até o dia em que vi uma interna vibrando de alegria quando pela primeira vez estampou o seu carimbo sobre uma solicitação de exame de sangue, que ela exibia exultante para todos. Outro aspecto importante - agora deixando o desvio e voltando ao prontuário - é que ele é escrito para uma audiência: outros médicos que irão não apenas tomar decisões baseadas neste documento, mas avaliar o estudante que o escreveu. Embora, como já foi dito antes, o modo de avaliação no ambulatório que estudei fosse menos protocolar do que nos estágios curriculares, 
presenciei repetidas vezes os preceptores solicitando a estudantes que refizessem o prontuário. Um médico que se inquietava sobremaneira com essa prática costumava dizer: "vocês todos vão ter que sair daqui sabendo escrever bem um prontuário".

A insistência não era apenas preciosismo do médico, pois é preciso contar com o fato de que embora a idéia do prontuário seja fornecer uma memória e um quadro da condição do doente, constantemente ele é mal organizado, as informações são dispersas, há falhas, lacunas. E além das omissões involuntárias, há algo mais que fica de fora: as informações complementares sobre o paciente, que podem ser decisivas para a condução de seu tratamento. O exemplo mais claro e corriqueiro disto diz respeito a considerações sobre o uso de medicamentos: se o paciente realmente os toma, se mente, porque não o faz. Nada disso é matéria do prontuário e, embora seja relevante na discussão de caso, não fica registrado, pois o que se escreve é apenas o que foi deliberado para o paciente.

Também não há registro de incertezas. Todo o processo da consulta e da discussão de caso fixa-se e torna-se determinado: o que é o problema e que procedimentos adotar diante dele. O tipo de raciocínio que levou a certas deliberações é velado, restando apenas o deliberado, o que pode dar origem, em consultas subseqüentes, a tentativas de recuperar o processo mediante o qual algumas decisões foram tomadas no passado, o que nem sempre é possível. Por exemplo, é possível que não fique claro, a partir das informações do prontuário, o que determinou a decisão de submeter um paciente à cirurgia ou não. A ausência dos processos de decisão pode indicar que isto seria supérfluo, posto que se supõe a existência de um conhecimento compartilhado, o que tornaria desnecessário descrever o modo como algo foi definido. Basta, então, apenas colocar o decidido, pois se crê que haja uma univocidade das práticas, o que de fato elas não têm.

Os prontuários são repositórios de fatos que servem a diferentes propósitos e podem ser mais ou menos adequados e completos, mas o modelo ideal é livre de erro, de ambigüidade, organizado de tal modo que se visualiza imediatamente tudo o que é relevante. Deve tornar possível reconstruir o caso de maneira clara e objetiva, porque supostamente é uma representação fiel da realidade de fatos e eventos. Esta visão do registro traz uma concepção da prática médica como transparente, unívoca, racional (Berg 1996); nele revela-se mais uma vez a objetificação do paciente, sua descrição como conjunto de doença, órgãos, sintomas, processos patológicos. É um paciente abstrato e, embora reduzido à materialidade, é quase insubstancial.

O modo como consensos, cálculos, exames, medicamentos e mesmo relatos de sintomas aparecem nas discussões de caso e no uso de prontuário 
está usualmente ligado à afirmação de objetividade e a uma recusa a se ater a questões consideradas como subjetivas. Foram tais aspectos que busquei ressaltar para mostrar como se constrói na prática esse senso de que a doença e o corpo são realidades materiais. Mas não faz parte do meu argumento a afirmação de que a medicina se reduz a isso ou que ela é bem-sucedida em destacar o objetivo do subjetivo. A dificuldade em realizar este divórcio está bastante presente na prática médica, principalmente quando entra em cena o personagem do paciente problemático (e há inúmeros modos de ser problemático). Neste caso, não há como renunciar à construção de narrativas paralelas, buscar motivos, situações específicas que tornem inteligível aquele enigma que toma a forma de um paciente (Souza 2004). A literatura sobre o tema é também pródiga em exemplos dessa impossibilidade de levar até o fim o projeto de completa objetificação, neutralidade e racionalidade.

\section{Retomando a narrativa e concluindo}

Para dar um fecho ao artigo, vou retornar ao caso interrompido no início:

Enquanto se desenrolava a discussão entre Fabiana e Alberto, ambos em pé diante do paciente, entrou na sala o dr. Tiago, um dos preceptores, para discutir o caso. Logo ao chegar, reconheceu a paciente, chamou-a pelo nome, Magali, e disse: "você está mais magra, está ótima, largou aqueles mocotós, aquelas feijoadas...". Ele refez o exame clínico e, enquanto isso, ainda gracejava com a paciente, dirigindo-se também a Fabiana: "Magá, isso aqui comia um acarajé sacudido, ela comia mais que vendia". Magali ria. O dr. Tiago primeiro auscultou a paciente e ensinou Fabiana a organizar a ausculta: o que ouvir primeiro, o que ouvir depois, como checar a ausculta etc. Como o exame tinha caráter didático, estendeu-se bem mais do que o usual. Mas o médico ainda assim não tratou a paciente como mero corpo, modelo para o ensino de uma técnica médica. Ele disse a Fabiana: "Magali já está tão acostumada com esse tipo de situação que ela não se importa de ser examinada por estudantes, não é Magá?". O sentido da fala era menos o de descrever a circunstância em que eles se encontravam, e mais de demandar paciência a quem emprestava seu corpo e seu tempo para o ensino médico. Magali permaneceu silenciosa, resignada. Fabiana, por sua vez, não prestou atenção à interação do dr. Tiago com Magali; estava concentrada em dominar a ausculta e não em aprender acerca de como manter um paciente engajado na situação, mesmo quando ele é tratado como objeto.

Depois do exame físico, o residente foi esclarecer com o dr. Tiago a dúvida sobre a obstrução das artérias de Magali. Ele respondeu: ela não tem nada, está 
ótima. O residente quis argumentar que havia lógica em seu raciocínio: como deu homogêneo, ele pensou que poderia ser uma completa obstrução e, portanto, seu estado seria gravíssimo. $\mathrm{O}$ dr. Tiago interrompeu o residente antes que ele concluísse a palavra gravíssimo, dizendo que se referia ao "problema dela", sem nomear. De súbito, Alberto parece perceber a paciente, volta o olhar rapidamente para ela e se dá conta de que ela existe, não é apenas um exame que ele interpreta, mas uma pessoa sentada ali ao lado. Repete, então, a sua questão, refraseando-a nos termos colocados pelo dr. Tiago. Mas o olhar dirigido à paciente foi só um breve lapso, logo ele volta ao que lhe interessa: mostrar que seu raciocínio acerca do exame estava correto. O dr. Tiago afirma que já conhece o caso e que duvida que ela de fato tenha tido um infarto, mantém a prescrição, tranqüiliza Magali, diz que ela está ótima, que tem que andar todos os dias e se despede dela.

O desenrolar da cena e outros elementos apontados ao longo do artigo podem levar nosso pensamento em várias direções. Podemos reafirmar alguns elementos que já são óbvios, como a tendência da medicina de tornar-se cada vez mais técnica e científica e de como esse processo leva ao estabelecimento, em sua prática, de certo compromisso com os valores da objetividade, da neutralidade. Em geral, para os que exercem uma prática clínica, a medicina que merece o nome de científica é basicamente um empreendimento que envolve o uso de raciocínio para estabelecer diagnósticos e para adequar a droga a cada caso, ou talvez seja mais próprio dizer, a droga adequada para um conjunto de exames laboratoriais e de imagens, como cateterismos, cintilografias, mioeletrocardiografias etc. Isto significa para os médicos afastarem-se do risco e instalarem-se em um domínio de certeza garantido pelos exames, tidos como evidências objetivas e descrições diretas das estruturas internas do corpo (Schreiber 1997).

Os medicamentos, principal estratégia de tratamento, também fazem parte do amplo leque de recursos fornecidos pela ciência e pela tecnologia, cuja eficácia é atestada por experimentos realizados com milhares de pessoas. Por conta do predomínio dessa concepção, a estudante mostra-se mais preocupada em aprender a auscultar do que em atentar para a paciente, de um modo que a traga de volta à cena de um modo menos impessoal e passivo. No residente, esta atitude de objetificação do corpo parece já mais cristalizada e é só por um lapso muito reduzido de tempo que ele se dá conta de que está diante de uma pessoa. O preceptor, entretanto, já maduro em sua carreira, possui virtudes e habilidades importantes para a prática que são, ao menos no momento, ignoradas por seus aprendizes.

Como então - somos levados a pensar — os estudantes se introduzem nesse mundo e aprendem a habitar essa atmosfera? Há um conjunto de ele- 
mentos que convergem para conduzi-los nessa direção. A crença na ciência, na tecnologia e na existência do mundo como agregado de fatos de natureza objetiva - que é o horizonte do nosso tempo — orienta e desvenda para o estudante o que ele vai encontrar na medicina. Além disso, há um caminho de aprendizado que privilegia a visão de corpo e doença como realidades essencialmente biológicas e materiais. Essa via acaba por encaminhá-lo ao hospital e aos ambulatórios, onde ele passa a atuar ao mesmo tempo como "médico" e como estudante.

A sua formação ganha, então, novos desdobramentos, pois agora, confrontado com pacientes reais, ele deve aprender a manejar na prática as noções de objetividade, corpo e doença e demonstrar aos seus instrutores que é capaz de se apoderar dos instrumentos disponíveis para a condução de uma consulta e a resolução de um caso. Mesmo sem ter a responsabilidade plena sobre o paciente, o estudante precisa evidenciar que possui a competência para transpor o relato dele ouvido para o jargão médico e editar, de modo apropriado, as informações coletadas, apresentando-as nas discussões de caso e registrando-as em prontuários.

Os estudantes habilitam-se a elaborar o perfil do paciente em termos adequados à concepção científica: um corpo puramente biológico que apresenta uma parte lesada. A lesão só é concreta e real se atestada por exames que permitam o conhecimento do que se passa ao interior do corpo. É a partir daí que se torna possível projetar uma intervenção, ela mesma de natureza material. Embora a medicina não se resuma a isso, como vimos em boa parte da literatura sobre o tema e no modo de o dr. Tiago lidar com a paciente, o treinamento do médico, naquilo que ele tem de explícito, está predominantemente voltado para a lida impessoal com um paciente que é, mediante uma forma específica de enquadramento, destituído de qualidades pessoais.

A questão é que essa objetividade é também uma construção, algo que depende de processos de interpretação. No entanto, isto fica encoberto (ao menos nas situações menos problemáticas) e tudo se passa como se o que é revelado nos exames - principalmente naqueles que envolvem uso de tecnologia mais avançada — ou em outras práticas de objetificação fosse uma descrição direta da realidade material da doença. O estudante que dá seus primeiros passos na prática clínica flutua entre esta concepção e aquela que admite que há uma elaboração por parte do intérprete daquilo que é mostrado (Joyce 2005; Monteiro 2004). Entretanto, mesmo nesses casos, o que se busca é fechar os horizontes e as perspectivas da doença, a fim de se assegurar de que aquilo que é percebido é o próprio objeto.

A tentativa de erradicação de qualquer ambigüidade, contingência ou sentido humano no modo de reconhecer e lidar com a doença revela uma 
face da medicina sintonizada com um movimento geral da nossa cultura em direção à racionalidade fundada no cálculo (Gadamer 1996). O perigo desta inclinação de natureza burocrática é a de que as habilidades que não se reduzem à racionalidade instrumental, mas envolvem outras formas de compreensão, como a intuição, não passíveis de plena explicitação, deixem de ser cultivadas e sejam drasticamente reduzidas devido a um excesso de confiança na calculabilidade de tudo.

No caso da medicina, embora seu exercício envolva uma compreensão que vai além do cálculo, este ganha cada vez mais espaço na clínica médica. Entretanto, há ainda lugar para uma prática que, embora seja pensada como algo de natureza estritamente pragmática e voltada para lidar com a dimensão física da doença, incorpora outras formas de compreensão que permitem, mesmo em meio à objetificação do paciente, a retomada de alguma dimensão existencial através de um fazer que abre espaço para a recusa ao anonimato, o humor, a consideração dos dramas vividos e a busca de alguma cumplicidade.

Recebido em 03 de julho de 2006

Aprovado em 13 de março de 2007

Iara Maria de Almeida Souza é professora do Departamento de Sociologia da Universidade Federal da Bahia e pesquisadora do ECSAS — Núcleo de Estudos em Ciências Sociais e Saúde/UFBa. E-mail: <iara-maria@uol.com.br>.

\section{Nota}

${ }^{1}$ Good, ao estudar essas práticas, preocupou-se fundamentalmente com a perspectiva dos estudantes sobre elas. Eu vou tratá-las não do ponto de vista de atores específicos, mas a partir da observação das interações e das conversas que envolviam a apresentação e o prontuário. 


\section{Referências bibliográficas}

ACIOLI, Giovanni Gurgel. 2004. "O lugar, a teoria e a prática do profissional médico: elementos para uma abordagem crítica da relação médicopaciente no consultório". Interface Comunicação, Saúde e Educação, 8(14):95-112.

ATKINSON, Paul. 1984. "Training for certainty". Social Science and Medicine, 19(9):949-956.

BERG, Marc. 1996. "Practices of reading and writing: the constitutive role of the patient record". Sociology of Health and Illness, 18:499-524.

BERG, Marc et alii. 2000. "Guidelines, professional and the production of objectivity: Standardisation and the professionalism of insurance medicine. Sociology of Health and Illness, 22(6):765-791.

BONET, Octavio. 2004. Saber e sentir: uma etnografia da aprendizagem da biomedicina. Rio de Janeiro: Editora Fiocruz.

CAMARGO Jr., Kenneth Rochel. 2005. "A biomedicina". Physis: Revista de Saúde Coletiva, 15:177-201.

CAPRARA, Andrea \& LINS e SILVA, Anamélia. 1999. "A relação médicopaciente: para uma humanização da prática médica". Cadernos de Saúde Pública, 15:1-17.

CASEY, Edward. 1998. "The ghost of embodiment: on bodily habitudes and schemata". In: D. Welton (org.), Body and flesh: a philosophical reader. Blackwell Publisher.

CORRÊA, José de Anchieta. 1995. "A relação médico-paciente e a produção do saber". Cadernos de Bioética, 3:29-44.

COX, Ken. 2001. "Stories as case knowledge: case knowledge as stories". Medical Education, 35:862-866.
CSORDAS, Thomas. 1993. "Somatic modes of attention". Cultural Anthropology, 8(2):135-156.

GADAMER, Hans George. 1996. El estado oculto de la salud. Barcelona: Gedisa.

GELLER, Gail; FADEN, Ruth \& LEVINE, David. 1990. "Tolerance for ambiguity among medical students: implications for their selection, training and practice". Social Science and Medicine, 31(5):619-624.

GILBERT, Ana Cristina Bohrer; CARDOSO, Maria Helena Cabral de Almeida \& WUILLAUME, Susana Maciel. 2006. "Mulher, medicina e tecnologia nos discursos de residentes em obstetrícia/ginecologia". Cadernos de Saúde Pública, 22(5):941-950.

GOOD, Byron. 1993. Medicine, rationality, and experience. Cambridge: Cambridge University Press.

GOULART, Lúcia M. H. Figueiredo. 1998. "Depois que forma, muda: estudo da relação médico-paciente no âmbito da prática docente-assistencial na Faculdade de Medicina - UFMG". In: A. Paiva e M. Soares (orgs.), Universidade, cultura e conhecimento: a educação pesquisa a UFMG. Belo Horizonte: Autêntica Editora.

HABER, Richard \& LINGARD, Lorelei. 2001. "Learning oral presentations skills - a rhetorical analysis with pedagogical and professional implications". Journal of General Internal Medicine, 16:308-314.

HOBBS, Pamela. 2002. "Islands in a string: the use of background knowledge in an obstetrical resident's notes". Journal of Sociolinguistcs, 6(2):267-274.

HOFFMANN, Leandro. 1993. "A morte na infância e sua representação para 
o médico - reflexões sobre a prática pediátrica em diferentes contextos". Cadernos de Saúde Pública, 19(3):364-374

JOYCE, Kelly. 2005. "Apealing images: magnetic resonance imaging and the production of authoritative knowledge". Social Studies of Science, 35(3):437-462.

KOIFMAN, Lílian. 2001. "O modelo biomédico e a reformulação do currículo médico da Universidade Federal Fluminense". História, Ciências, SaúdeManguinhos, 8(1):48-70.

LINGARD, Lorelei; GARWOOD, K.; SCHREYER, C. B. \& SPAFFORD, M. M. 2003. "A certain art of uncertainty: case presentation and the development of professional identity". Social Science and Medicine, 56:603-616.

MARTINS, André. 2004. “Biopolítica: o poder médico e a autonomia do paciente em uma nova concepção de saúde". Interface - Comunicação, Saúde, Educação, 8(14):21-32.

MARTINS, Paulo Henrique. 2003. Contra a desumanização da medicina - crítica sociológica das práticas médicas modernas. Petrópolis: Vozes.

MENEZES, Rachel Aisengart. 2001. "Etnografia do ensino médico em CTI". Interface - Comunicação, Saúde, Educação, 5(9):117-130.

MERHY, Emerson Elias. 2000. "Um ensaio sobre o médico e suas valises tecnológicas". Interface - Comunicação, Saúde, Educação, 4(6):109-116.

MONTEIRO, Rosana Horio. 2004. "Imagens diagnósticas e a construção social do conhecimento médico. Um estudo etnográfico do cateterismo cardíaco". Política \& Trabalho, 20:141-158.
QUINTANA, Alberto Manuel; CECIM, Patrícia da Silva \& HENN, Camila Guedes. 2002. "O preparo para lidar com a morte na formação do profissional de medicina". Revista Brasileira de Educação Médica, 26:204-10.

RONZANI, Telmo Mota \& RIBEIRO, Mário Sérgio. 2003. "Identidade e formação profissional dos médicos". Revista Brasileira de Educação Médica, 27(3):229-236.

SCHERER, Magda Duarte dos Anjos; MARINO, Selma Regina Andrade \& RAMOS, Flávia Regina Souza. 2005. "Rupturas e resoluções no modelo de atenção à saúde: reflexões sobre a estratégia da saúde da família com base nas categorias kuhnianas". Interface Comunicação, Saúde, Educação, 9(16):53-66.

SCHREIBER, Lilia Blima. 1997. "No encontro da técnica com a ética: o exercício de julgar e decidir no cotidiano do trabalho em medicina". Interface Comunicação, Saúde, Educação, 1(1):123-140.

SINCLAIR, Simon. 1997. Making doctors - an institutional apprenticeship. Boston: Berg Publications.

SOUZA, Alícia Navarro. 2001. "Formação médica, racionalidade e experiência". Ciência \& Saúde Coletiva, 6(1):87-96.

SOUZA, Iara Maria de Almeida. 2004. Relação médico-paciente na clínica em cardiologia: entrelaçamento entre ciência, técnica e prática em um contexto de formação médica. Tese de doutorado defendida no Programa de Pós-graduação em Ciências Sociais da Universidade Federal da Bahia. 
Resumo

O artigo trata de dois tipos de prática envolvidos na formação do médico a apresentação de caso e o registro da consulta em prontuário - que são de fundamental importância no processo de destituição dos pacientes de suas qualidades pessoais e sua reconstituição como corpo objetivo, conjunto de órgãos, portador de lesão e objeto de intervenção. O material etnográfico apresentado aqui é fruto da observação de apresentações de caso de estudantes para seus preceptores em um ambulatório de cardiologia do Hospital Universitário da UFBA. O artigo chama a atenção para o papel das concepções científicas e da tecnologia nesse processo. Mostra também que tanto a apresentação de caso ao preceptor (um tipo de fala ao mesmo tempo descritiva, performativa), como a escrita em prontuário (uma prática formativa que molda a fala e a reflete, autorizando o estudante) são procedimentos de objetificação do paciente que dependem de interpretação, embora isto se dê de forma velada.

Palavras-chave: Formação do médico, Biomedicina, Corpo, Objetificação, Prática médica

\section{Abstract}

The article analyzes two types of practice involved in medical training - case presentations and the annotation of consultations in medical records - that play a fundamental role in divesting patients of their personal qualities and reconstituting them as an objective body, a set of organs, the site of a lesion and the object of intervention. The ethnographic material presented here is the result of observing case presentations made by students to their tutors in a cardiology outpatient clinic at the University Hospital of UFBA. The article highlights the role of scientific and technological conceptions in this process. It also shows that both the case presentations to tutors (a descriptive and performative type of speech) and the written notes in medical records (a training practice that both shapes speech and reflects it, thereby authorizing the student) are procedures for objectifying the patient that depend on interpretation, although this takes place in surreptitious form.

Key words: Medical training, Biomedicine, Body, Objectification, Medical practice 